\title{
THE IMPACT OF MEETING ACCREDITATION STANDARDS ON THE QUALITY OF THE ELECTRONIC HEALTH RECORDS
}

\author{
MOHAMED HOSSAM ATTIA ${ }^{1}$, ABDELNASSER IBRAHIM ${ }^{2 *}$ \\ ${ }^{1}$ Area Quality Manager, Magrabi Hospitals and Centers, 7934 Al Nuzlah Al Yamania Dist, Jeddah , Saudi Arabia. MBA, Edinburgh Business \\ School, Heriot-Watt University Gait 11, The Avenue, Currie EH14 4AS, United Kingdom. ${ }^{2}$ PHD Pathology, REACHE Northwest, Salford Royal \\ Hospital, Stott Lane, Salford, M6 8HD, Greater Manchester, United Kingdom. Email: nasseribrahim5983@gmail.com
}

Received: 02 February 2020, Revised and Accepted: 17 March 2020

ABSTRACT

Objective: Electronic health records (EHRs) are considered a way to make the management of patient information easier, improve efficiency, and decrease costs related to medical information management. Compliance with requirements from accreditation bodies on quality of documentation ensures the complete and accurate patient information in the EHR. The purpose of this study is to measure the effect of quality accreditation on the quality of documentation in the EHR.

Methods: A simple random sample of $18 \%$ of patient records was manually selected each month during the entire study period from the population of discharged patients. The auditing process included 18 months starting from January 2014 until June 2015. The data collection was performed by a quality management unit using a modified medical record completeness checklist adapted from Joint Commission International (JCI) criteria.

Results: The results of the study show the improvement in compliance with complete medical records' documentation after the JCI accreditation. However, after the accreditation, the compliance suffers a dramatic fall which could be referred to the post-accreditation slump. The compliance then improved again to reach higher levels of compliance. Using paired t-test, the mean of total compliance with complete and accurate medical records in October 2014 was less than in May 2015.

Conclusion: This study highlighted the performance of one process before and after the first accreditation of the organization showing the real difference between the performance before and after the accreditation and explaining the drop that happened just after the accreditation.

Keywords: Accreditation, Quality Improvement, Medical documentation

(C) 2020 The Authors. Published by Innovare Academic Sciences Pvt Ltd. This is an open access article under the CC BY license (http://creativecommons. org/licenses/by/4. 0/) DOI: http://dx.doi.org/10.22159/ajpcr.2020.v13i5.37013

\section{INTRODUCTION}

Accreditation is an acknowledged assessment process used in many countries to evaluate the quality of care [1]. Healthcare leaders believe that minimizing variations through policies, procedures, guidelines, pathways, and standards are a good strategy to improve healthcare quality $[2,3]$.

Healthcare leaders use accreditation as a method to improve the quality of care. Accreditation is an essential part of healthcare systems in more than 70 countries [4]. There is persistent proof that healthcare system could be improved by accreditation programs. These healthcare system improvements boost the adoption of accreditation programs as a mechanism that has the potential to improve the quality of healthcare [5].

Joint Commission International (JCI) is a part of a global enterprise of non-profit organizations that address all dimensions of accreditation, quality care, and patient safety [6]. The JCI accreditation survey includes the following: Evaluation of documents provided by organization staff that shows compliance, verbal information about the implementation of standards or examples of their implementation that enables compliance to be determined, onsite observations by surveyors, tracking of patients through the care process by the tracer methodology, education about standards compliance, and performance improvement [7].

The objective evaluation process, based on the JCI standards, helps healthcare organizations to evaluate, measure, and improve health performance [8]. Many hospitals have considered the JCI accreditation process to be a strategy for improving the quality of care and safety for patients and healthcare workers $[5,9]$.
Electronic health record (EHR) contains retrospective, concurrent, and prospective information, and its primary purpose is to support continuing, efficient, and quality integrated healthcare [10]. Introducing EHR aims to help doctors and healthcare facilities in providing quality health care to patients as well as sustaining their safety [11].

EHR is considered a way to make the management of patient information easier, improve efficiency, and decrease costs related to medical information management [12]. The Institute of Medicine defined quality care as "the degree to which health services for individuals and populations increase the likelihood of desired health outcomes and are consistent with current professional knowledge" [11].

In the growth of scientific medicine, medical records play an important role as a tool and a basis for planning patient care besides medical education, research, and legal protection [13].

The aim of the present study is to compare the compliance with proper and complete documentation before and after the JCI accreditation in Magrabi Aseer Hospital, a subspecialized hospital in Saudi Arabia

\section{MATERIALS AND METHODS}

Materials

The study was conducted in a private 30-bed, subspecialized hospital in Abha, Aseer Saudi Arabia. The annual inpatient census is approximately 2000. The scope of health care service was provided to all patient age groups, nationalities, and payment types. The hospital provided only ophthalmology inpatient services.

The data collection was performed by a quality management unit using a modified medical record completeness checklist adapted 
from JCI criteria. The list contains seven major categories: General criteria, medication documentation, discharge summary and operative report, plan of care, patient assessment, consent, and surgical safety. These seven categories included 56 criteria to be checked.

\section{Methods}

Slovin's formula was used to calculate the sample size per month based on a $95 \%$ confidence interval (CI) from an average monthly inpatient census of 150 patients $[14,15]$.

A simple random sample of $18 \%$ of patient records was manually selected each month during the entire study period from the population of discharged patients. The quality department staff audited the selected files and they were unaware of the objectives of the study.

The auditing process included 18 months starting from January 2014 until June 2015. The hospital started the JCI preparation process at January 2014 and the hospital successfully passed the JCI survey in January 2015.

\section{RESULTS}

Fig. 1 shows the improvement in compliance with complete medical records' documentation after the JCI accreditation. However, in March 2015 , the compliance suffers a dramatic fall reaching $93 \%$ which could be referred to the post-accreditation slump. The drop reached 93\% compliance in March 2015 and then improved in April, May, and June 2015 which were $98 \%, 99 \%$, and $98 \%$, respectively.

The descriptive analysis in Figs. 2, 3 and 4 shows the changes in the mean between 2 months October-14 and May-15 are statistically significant.

The mean of total compliance with complete and accurate medical records in October 2014 was less than in May 2015 at the 0.05 level of significance. CI quantifies the uncertainty associated with estimating the difference in means from sample data. The analysis shows $90 \%$ confident that the true difference was between -0.078611 and -0.025130 , while $95 \%$ confidence was $<0.025130$. Distribution of the data, comparing the location and means of the samples looking for unusual data before interpreting the results of the test.

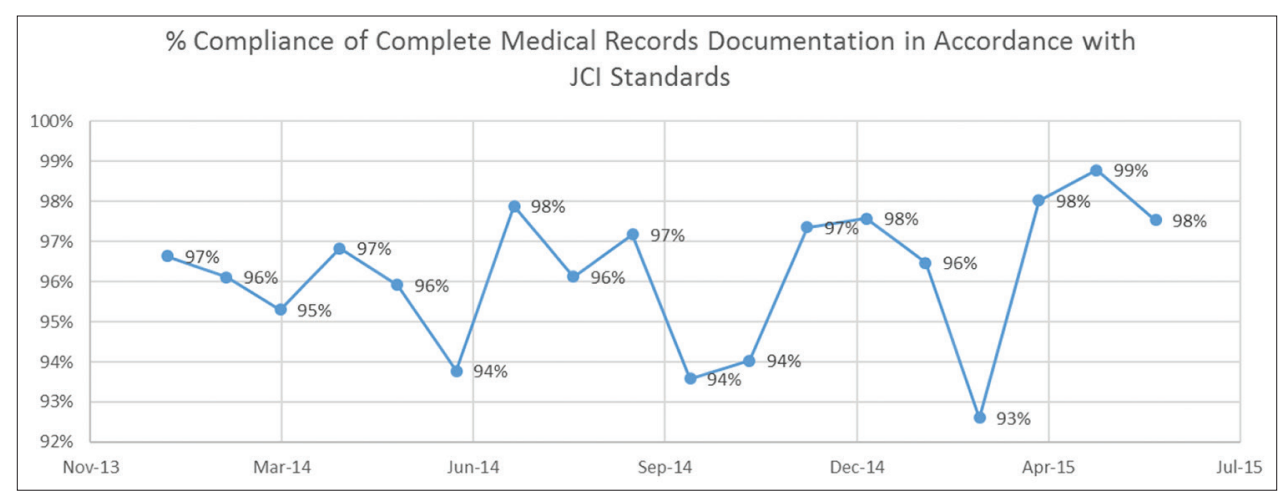

Fig. 1: Total compliance through the whole auditing period

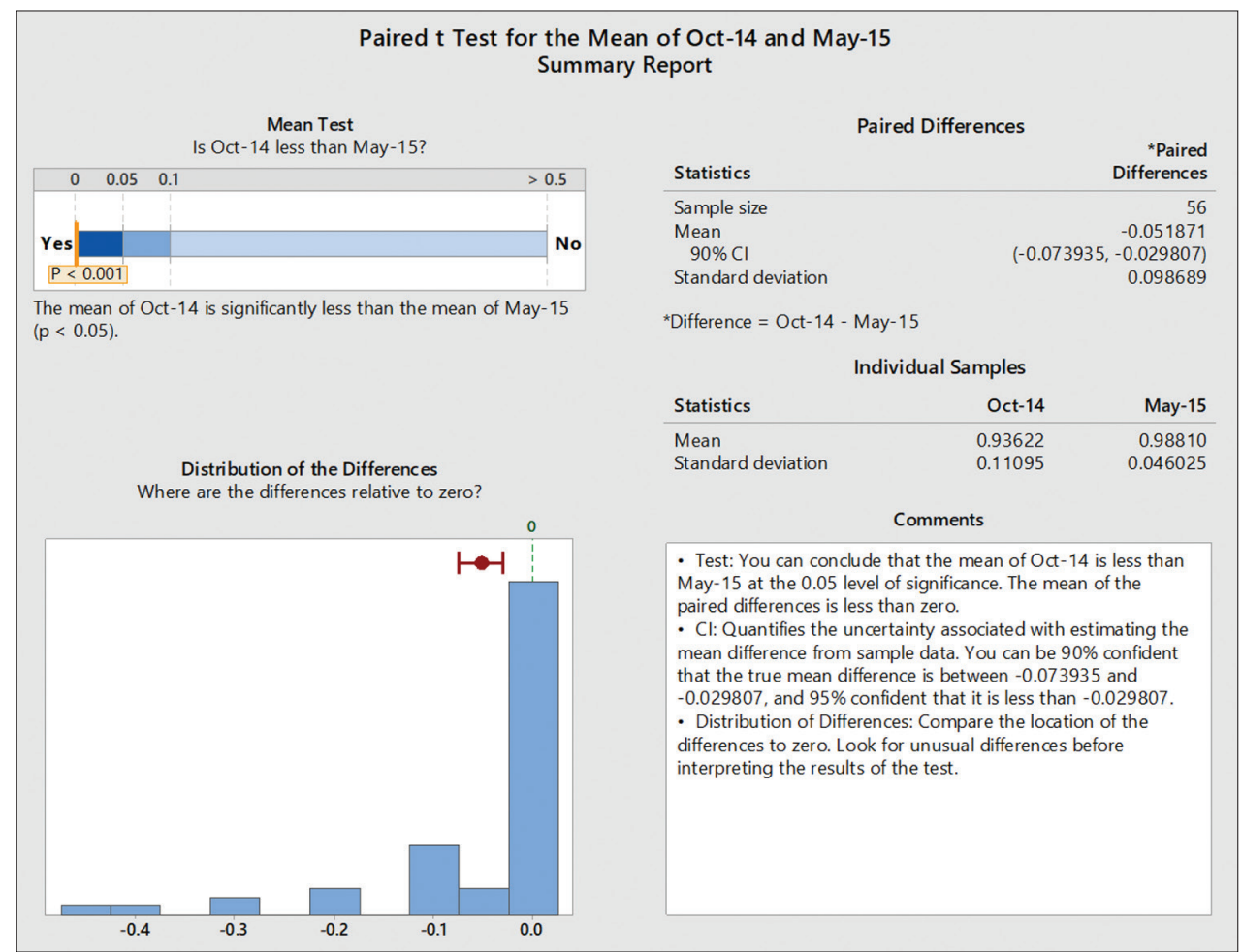

Fig. 2: Comparison of the distribution of the difference and the means between October 2014 and May-2015 


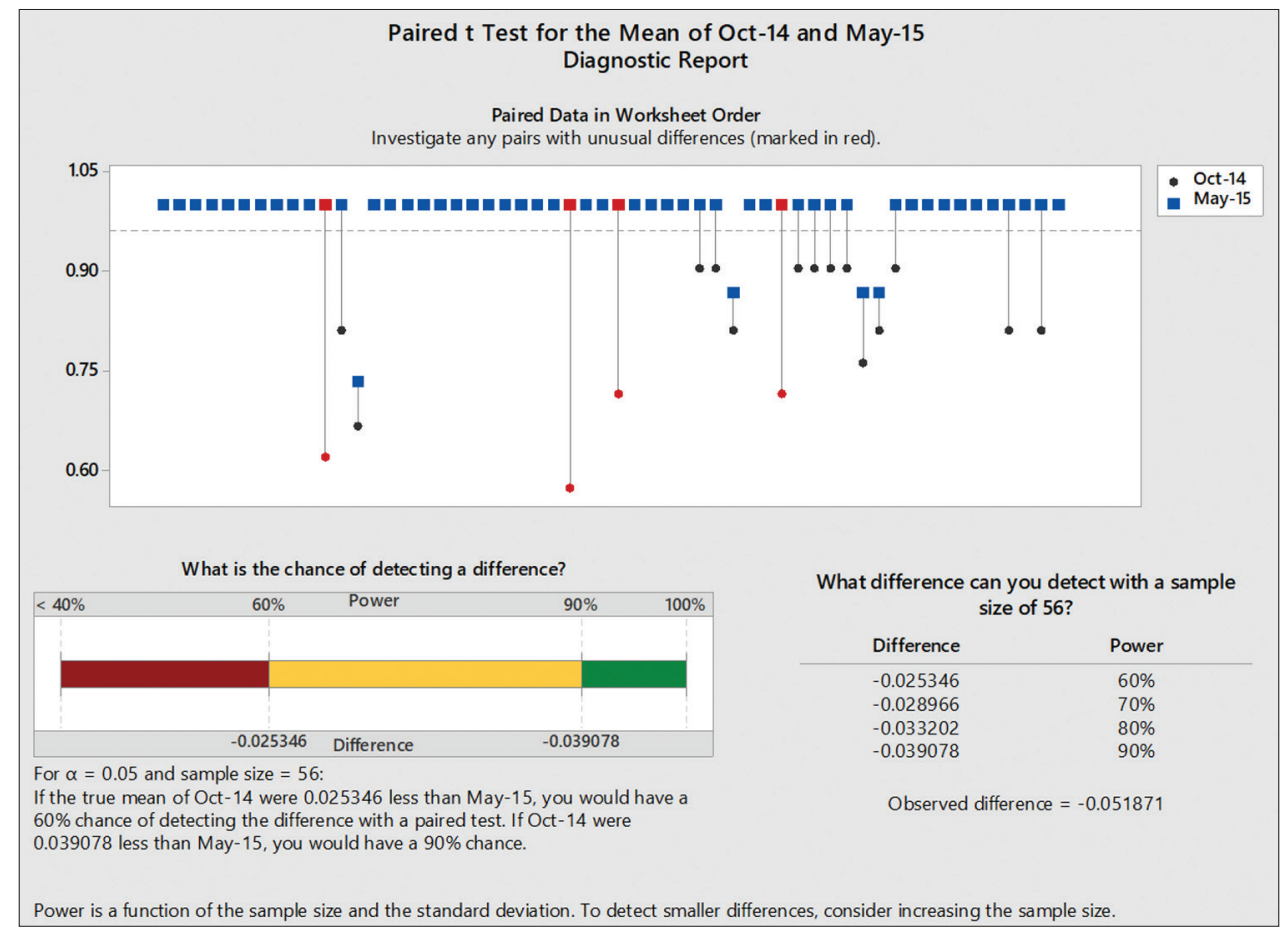

Fig. 3: Paired t-test for the mean of October 2014 and May 2015

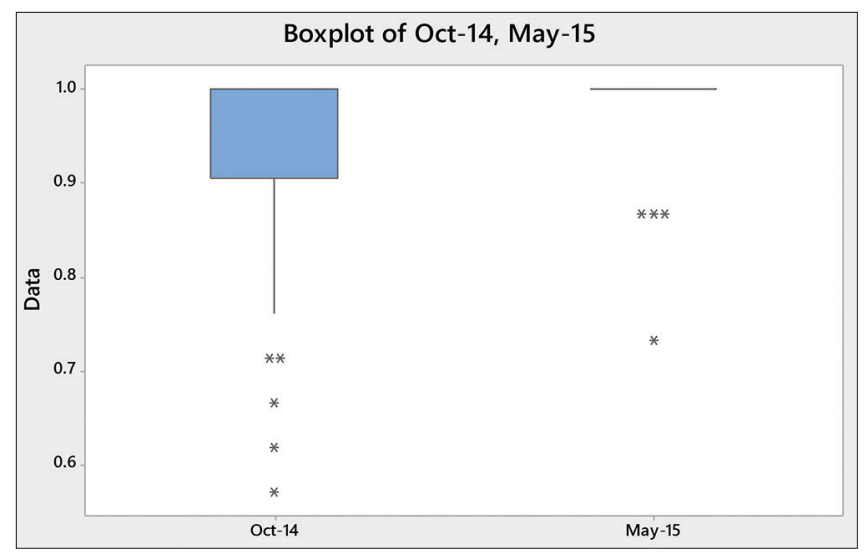

Fig. 4: Box plot graph for before and after accreditation

\section{DISCUSSION}

There is no evidence of the value of accreditation programs published in the peer-reviewed literature. The lack of publications raises the question about the accreditation, is it worth the time cost and human resources? [4].

Scarce studies specifically addressed the correlation between accreditation and certification of hospitals and patient outcomes. Large quality accreditation programs founded to improve the quality of healthcare are using more healthcare resources rather than any clinical care provided to the patients; therefore, quality accreditation has a substantial effect on patient safety and clinical outcomes [16].

The results of the network for the evaluation of accreditation and standards in healthcare study show that accreditation was significantly positively correlated with organizational culture and leadership. There was a positive trend between accreditation and clinical performance. Organizations with strong leadership perform better on accreditation programs than other organizations lacking leadership commitment; this indicates that accomplishment of accreditation provides an accurate reflection of organizational behavior believed to be important in enabling quality of care [17].

The Devkaran study results have answered the question: Do hospitals maintain quality and patient safety standards over the accreditation cycle? The research shows that, although performance falls after the accreditation survey, the tangible impact of accreditation should be appreciated for its capacity to sustain improvements over the accreditation cycle. This phenomenon is supported by other researchers who stated that those institutions which invest in the accreditation surveys reap the most benefits from accreditors' diagnosis, sharing of leading practices, and the ensuing changes [15].

The effect of accreditation varies from one facility to the other and as per Pomey's research where the research addresses five different facilities; one of the issues that were revealed by the study is what he called the paradox of success where the accreditation process recognized the accomplishments of the palliative care assessment team, following which the team lost momentum as a result of its funding being redirected to more problematic areas. This showcases the fact that accreditation should not only be used to find problems but also to validate and recognize success. Without this mandate, the accreditation process will undermine the very goals it hopes to reach [18].

Based on the results of this study, the performance improved before the accreditation and suffered a sudden drop just after the accreditation and then improved again to sustain the improvements.

\section{CONCLUSION}

This study highlighted the performance of one process before and after the first accreditation of the organization showing the real difference between the performance before and after the accreditation and explaining the drop that happened just after the accreditation. The study has also urged the concept of continuous quality improvement and continuous readiness which can result in a marked progress in the organization. 


\section{RECOMMENDATION}

To have better results, these data should be measured for longer period of time where at least two accreditation cycles have passed to see if there is a difference between the two accreditations also to compare the $1^{\text {st }}$ accreditation of an organization with the second and third accreditation, as whether the changes will be impeded in the process or will it be forgotten after the accreditation directly.

As for the accreditation bodies, they should have a continuous readiness program to support hospitals where random visits will be arranged throughout the accreditation period and self-assessment tools that are simple yet comprehensive to stimulate the organization to self-monitor and improve even after the accreditation.

\section{AUTHORS' CONTRIBUTIONS}

Mohamed Hossam Attia designed and performed the experiments, derived the models, and analyzed the data. Abdulnasser Ibrahim contributed to the design and implementation of the research. Mohamed Hossam Attia wrote the manuscript in consultation with Abdulnasser Ibrahim. All authors discussed the results and commented on the manuscript.

\section{CONFLICTS OF INTEREST}

None.

\section{AUTHORS' FUNDING}

No funding was needed for this research.

\section{REFERENCES}

1. Jiang T, Yu P. The relationship between using electronic health records and meeting accreditation standards for client safety in residential aged care homes. Stud Health Technol Inform 2015;214:134-8.

2. Shaw CD, Kutryba B, Braithwaite J, Bedlicki M, Warunek A. Sustainable healthcare accreditation: Messages from Europe in 2009. Int J Qual Health Care 2010;22:341-50.

3. Bogh SB, Falstie-Jensen AM, Hollnagel E, Holst R, Braithwaite J, Johnsen SP. Improvement in quality of hospital care during accreditation: A nationwide stepped-wedge study. Int J Qual Health Care 2016;28:715-20.

4. Greenfield D, Braithwaite J. Developing the evidence base for accreditation of healthcare organisations: A call for transparency and innovation. Qual Saf Health Care 2009;18:162-3.

5. Nomura AT, Pruinelli L, Da Silva MB, de Fátima Lucena A, de Abreu Almeida M. Quality of electronic nursing records: The impact of educational interventions during a hospital accreditation process. Comput Inform Nurs 2018;36:127-32.

6. Joint Commission International; 2018. Available from: https://www. jointcommissioninternational.org/about-jci/who-is-jci. [Last accessed on 2018 Nov 19].

7. Joint Commission International Accreditation Standards for Ambulatory Care. $3^{\text {rd }}$ ed.; 2015.

8. The Joint Commission. Accreditation Process Overview. The Joint Commission Web Site. Available from: https://www.jointcommission. org/accreditation process overview. [Last accessed on 2018 Nov 19].

9. Lucena $\mathrm{AD}$. The nursing process: Interfaces with the hospital accreditation process. Rev Gaucha Enferm 2013;34:8-9.

10. Yu P, Hailey D, Wang N, Oxlade D. Developing approaches to measure the quality of electronic versus paper-based nursing documentation in aged care homes. Electron J Health Inform 2009;6:e7.

11. Aldosari B. Patients' safety in the era of EMR/EHR automation. Inform Med Unlocked 2017;9:230-3.

12. Bain C. The implementation of the electronic medical records system in health care facilities. Procedia Manuf 2015;3:4629-34.

13. Mogli GD. Medical records role in healthcare delivery in $21^{\text {st }}$ century. Acta Inform Med 2009;17:209.

14. Stephanie E. Slovin's Formula Sampling Techniques. Santa Monica: Leaf Group Ltd.; 2003.

15. Devkaran S, O'Farrell PN. The impact of hospital accreditation on quality measures: An interrupted time series analysis. BMC Health Serv Res 2015;15:137.

16. Øvretveit J, Gustafson D. Using research to inform quality programmes. BMJ 2003;326:759-61.

17. Braithwaite J, Greenfield D, Westbrook J, Pawsey M, Westbrook M, Gibberd R, et al. Health service accreditation as a predictor of clinical and organisational performance: A blinded, random, stratified study. Qual Saf Health Care 2010;19:14-21.

18. Pomey MP, Lemieux-Charles L, Champagne F, Angus D, Shabah A, Contandriopoulos AP. Does accreditation stimulate change? A study of the impact of the accreditation process on Canadian healthcare organizations. Implement Sci 2010;5:31. 